\title{
Atenção básica e saúde mental: experiência e práticas do Centro de Saúde Escola Samuel B. Pessoa
}

\author{
Maria Luisa Sandoval Schmidt \\ Instituto de Psicologia da Universidade de São Paulo (São Paulo, SP)
}

\begin{abstract}
O presente artigo apresenta e analisa achados de estudo etnográfico realizado junto ao Centro de Saúde Escola Samuel B. Pessoa, focalizando as relações entre o campo da saúde mental e a atenção básica em saúde. Está dividido em três partes principais, contemplando a história dessas relações na referida instituição, aspectos atuais das políticas públicas de saúde que incidem sobre essa esfera e a prática de supervisão de saúde mental para agentes comunitários de saúde como espaço privilegiado de formação e diálogo para a composição de práticas de cuidado. O estudo mostrou que a experiência e as práticas do CSEB, relacionando saúde mental e atenção primária e básica em saúde, conservam a memória histórica desta relação na cidade de São Paulo, experimentando, ao mesmo tempo, as novas propostas para área, desde uma perspectiva crítica e problematizadora.
\end{abstract}

Palavras-chave: Saúde mental, Atenção básica em saúde, Políticas públicas de saúde, Supervisão, Etnografia.

Primary health and mental care: experience and practice in the Health Center School Samuel B. Pessoa

This paper presents and analyzes findings from an ethnographic study conducted inside the Health Center School Samuel B. Pessoa, focusing on the relationship between mental health and primary health care. It is divided into three main sections covering the history of these relations in that institution, current aspects of public health policies related to this area and the practice of supervision for community mental health workers as a privileged space for training and dialogue on the designing of care practices. The study showed that the experience and practices of CSEB, linking mental health and primary care and basic health, preserve the historical memory of this relationship in Sao Paulo, trying at the same time, the new proposals for the area, from a critical perspective.

Keywords: Mental health, Primary health care, Public health policies, Supervision, Ethnography.

$\mathrm{N}$ o contexto de um projeto de pesquisa sobre acesso aos serviços de saúde mental na cidade de São Paulo, ${ }^{1}$ realizei um estudo etnográfico no Centro de Saúde Escola Samuel Barnsley Pessoa (CSE Butantã), situado na zona oeste da cidade.

As relações entre saúde mental e atenção básica em suas dimensões teóricas e de interesse para a organização de serviços, bem como a consideração das possibilidades e vicissitudes desta associação no âmbito da recente história das políticas públicas de saúde no município de São Paulo, mostraram-se temas relevantes para a abordagem da questão do acesso, especialmente no que diz respeito à posição da saúde mental a partir da progressiva implantação do Programa de Saúde da Família (PSF) e da Estratégia da Saúde da Família (ESF).

O estudo etnográfico contribuiu para o entendimento dessa relação problemática e, numa interpretação que deriva do próprio percurso da pesquisa, decisiva para a saúde mental, considerando-se, por um lado, sua tradição de apresentar-se também, na história da reforma psiquiátrica paulista (e paulistana), como dispositivo de atenção primária e, por outro, seus rumos e destinos nas propostas de apoio matricial. 
A escolha do Centro de Saúde Escola, por sua vez, permitiu a aproximação de ideias e práticas de contato entre atenção básica e saúde mental que, em certo sentido, condensam e abrigam expressões significativas da história desse campo.

O estudo envolveu, entre 2009 e 2010, entrevistas individuais com a coordenadora do Projeto São Remo, que é a versão do PSF naquela instituição, a coordenadora do Programa de Saúde Mental, a supervisora de saúde mental do grupo de agentes comunitários de saúde (ACSs) e entrevistas coletivas com ACSs; observação participante das supervisões dos ACSs na saúde mental; e anotações de observações participantes realizadas por alunos de graduação do curso de psicologia do Instituto de Psicologia da USP, sob minha orientação, junto à supervisão dos ACSs na saúde mental, nos anos de 2007, 2008 e 2009.

Este texto combina apresentação e interpretação das práticas e das concepções dos trabalhadores do centro de saúde, buscando, ao modo de uma descrição densa, traduzir pontos de vista e vozes em suas complexidades e riquezas e transcrever vinhetas e fragmentos significativos daquilo que foi testemunhado. Traduzir e transcrever são ações que procuram fazer jus à experiência de campo, constituindo-se em ensaios, experimentos e exercícios de escrita que tateiam significados e sentidos que ora encontram, ora traem, aquilo que os próprios interlocutores pensam, sentem e vivem (Clifford, 2002; Geertz, 1989; 2002).

Por respeito ao diálogo e à interlocução como atmosfera do trabalho intelectual que se quer realizar sobre o tema aqui proposto, uma primeira versão desta comunicação foi discutida com profissionais do Programa de Saúde Mental e suas contribuições foram aqui incorporadas.

A decisão de identificar o Centro Escola e indicar apenas os cargos e categorias profissionais dos participantes da pesquisa foi feita a partir de conversas e ponderações com os mesmos sobre as dimensões éticas do trabalho. Essa solução, negociada, atendeu às expectativas de compor uma certa proteção de suas identidades com a atribuição dos devidos créditos à trajetória original e significativa, para o campo da saúde pública, desta instituição e de seus trabalhadores.

\section{Centro de saúde escola e saúde mental}

Os centros de saúde foram, e seus remanescentes ainda são, equipamentos da rede pública de saúde de primeira linha ou de atenção primária, ligados à esfera estadual de governo. A quase totalidade deles foi municipalizada com a implantação do Sistema Único de Saúde (SUS), tornando-os Unidades Básicas de Saúde (UBSs).

$\mathrm{Na}$ cidade de São Paulo, existem alguns centros de saúde ligados ao ensino e à pesquisa, cumprindo funções de atendimento a usuários aliados à sua constituição como campo de investigações e de formação para estudantes e residentes das áreas de medicina e enfermagem, bem como para estágio de alunos de outras áreas afeitas à saúde como psicologia, fonoaudiologia, terapia ocupacional e fisioterapia, para citar algumas. São os chamados Centros de Saúde Escola.

Os centros escola, quase sempre, têm autonomia para implementar políticas públicas a partir de uma perspectiva crítica ou própria, construindo e sedimentando uma experiência que costuma unir prestação de serviço à criação de instrumentos práticos e teóricos "de ponta". Alguns profissionais dessas instituições referem-se à criação de tecnologias como modos de problematizar, discutir, analisar e fazer que podem ser transpostos para outras instituições do sistema de saúde. 
Os modos de problematizar, discutir, analisar e fazer que unem atenção primária, saúde mental e, mais recentemente, a atenção básica representada pelo PSF são aquilo que se quer compreender, e o CSE, um lugar onde estudá-los.

A apresentação do CSEB será feita, então, pelo viés da história da relação entre saúde mental e atenção primária, acompanhando de perto a entrevista concedida pela coordenadora do Projeto São Remo, que articula o trabalho dos agentes comunitários de saúde nesta instituição, e as contribuições trazidas pela equipe de saúde mental para a construção dessa memória.

A história do Programa de Saúde Mental no CSEB confunde-se com a própria história da saúde mental com a atenção primária, e é marcada, nesse local, por três momentos.

O primeiro, por volta de 1978 e 1987, começa com a fundação do CSEB e seu interesse em "herdar" uma equipe de saúde mental que atuava em outro centro escola. $\mathrm{O}$ interesse foi duplo: ter uma equipe de saúde mental atendendo em primeira linha e tê-la como parceira na proposição de "tecnologia para atenção primária".

Profissionais da saúde mental lembram que a história da equipe começara no centro de saúde de Pinheiros, com uma visão da psiquiatria comunitária na abordagem da chamada doença mental. Nos anos 1980, existiu ali um setor de reabilitação, bem como um programa de atenção ao psicótico que era um "portas abertas", buscando dar atenção e cuidado ambulatorial às pessoas com transtornos graves. Este programa inspirou o Programa de Intensidade Máxima $(\mathrm{PIM})^{2} \mathrm{e}$ as interconsultas.

Depois, com a transferência para o Butantã, veio a colaboração com a atenção básica a partir de uma perspectiva epidemiológica. As profissionais lembram ainda que viveram, no contato com as outras equipes do CSEB, uma rica experiência de ação programática, diferente de uma mera justaposição de programas, realizando um trabalho conjunto de proposição, execução e avaliação de práticas de cuidado, com a introdução da psicanálise, da sociologia e de outras disciplinas, na busca por uma abordagem convergente dos diferentes setores.

O Programa de Saúde Mental, assim batizado desde seu início no CSEB, teria, ainda segundo sua equipe, se pautado pela visão das determinações sociais do processo saúde/doença e pelo modelo de atenção pública em saúde mental.

Retomando a periodização esboçada pela coordenadora do Projeto São Remo, neste primeiro momento, a saúde mental, como um dos programas do CSEB, constituiu-se como uma das portas de entrada para a população.

Por um lado, na perspectiva do desenvolvimento de tecnologia para atenção primária, houve uma colaboração intensa e profícua, principalmente com o Programa de Saúde do Adulto. As consultas no setor de adultos eram bastante detalhadas, e a equipe de saúde mental ajudou a elaborar um roteiro de anamnese, estabeleceu a possibilidade de interconsultas e supervisões, tendo em vista o acompanhamento de casos, e recebeu encaminhamentos. $\mathrm{O}$ modelo da atenção integral, hegemônico no CSEB naqueles anos, fazia apelo a tarefas compartidas entre diferentes profissionais, e a colaboração entre programas tinha este teor.

A proposta do CSEB era comum a todos os programas: a sala de espera era coletiva, as auxiliares de enfermagem faziam formação nos vários setores do CSEB e as supervisões conjuntas dos trabalhadores da saúde mental e sanitaristas, na perspectiva da saúde integral, eram um espaço importante na construção do serviço.

A equipe de saúde mental foi influenciada pela equipe do CSEB, modificou-se, compôs com o CSEB e sofreu influência da medicina preventiva. O modelo do Programa de Saúde

2 O Programa de Intensidade Máxima (PIM) realizava atendimento ambulatorial intensivo com pacientes e suas famílias, buscando evitar a internação hospitalar, numa perspectiva sintônica com a reforma psiquiátrica. Sobre a reforma psiquiátrica desde a perspectiva governamental, ver: Instituto Nacional de Assistência Médica da Previdência Social (1983). 
Mental foi gestado no CSEB e teria sido o primeiro equipamento a ter um programa de saúde integral do adulto. A equipe de atenção primária, por sua vez, beneficiou-se "com os instrumentos, a retaguarda, o conhecimento da área de saúde mental".

A partir de 1987, no horizonte das mudanças anunciadas pelo Sistema Único de Saúde (SUS), então em gestação, o CSEB passou por uma reformulação, deslocando a ênfase da atenção integral para a preocupação com uma maior cobertura, maior produtividade e recorte mais preciso do objeto das ações. Identifica-se, aqui, o segundo momento da história do CSE.

No plano concreto, a reformulação implicou uma restrição das consultas individuais, que, no modelo de atenção integral, eram extensas e minuciosas.

As antigas consultas abriam espaço para que o usuário tratasse de temas da vida como trabalho, sexualidade e família, e, dessa forma, não só o "problema" de saúde aparecia no contexto maior da história de vida, mas, também, aparecia ou podia aparecer como talhado para uma abordagem psicológica, para a qual contribuíam as supervisões e interconsultas com a equipe de saúde mental.

No novo modelo, com a focalização clínica das consultas, as questões da vida migraram para os grupos que se tornaram frequentes. Houve, ainda, o estabelecimento de prioridades no atendimento com base em estudos epidemiológicos. O serviço organizou-se em torno de programas voltados para grupos específicos: crianças, idosos, mulheres, adolescentes.

Um dado importante dessa reformulação é a passagem da gestão do CSEB da Secretaria de Saúde do Estado para a Faculdade de Medicina da Universidade de São Paulo (USP). Isso trouxe a estrutura departamental comum nas instituições universitárias, bem como certa multiplicidade de propostas teóricas e práticas, e de interesses também usuais na estrutura departamental.

No período de 1987 a 1994, em que se consolidou a proposta de atenção organizada em programas prioritários e grupos específicos, do ponto de vista da coordenadora do Projeto São Remo, a saúde mental experimentou uma espécie de "retrocesso" na colaboração com os outros programas do CSEB: as consultas individuais, sendo mais restritas, clínicas, não deixavam espaço para as vivências da população que passaram a ser discutidas nos grupos de envelhecimento, "de ser mulher", "de ser homem", entre outros. Essas mudanças reduziram as oportunidades de contato com a equipe de saúde mental e de encaminhamento da clientela.

Da perspectiva da atenção básica, representada pela coordenadora do Projeto São Remo, teria havido uma psiquiatrização do setor de saúde mental. O termo e o fenômeno psiquiatrização são contestados pela equipe de saúde mental como característico deste período.

É importante, talvez, fazer um comentário sobre a polissemia da expressão psiquiatrização e o que ela parece denotar naquele momento da relação entre atenção básica e saúde mental no CSEB. Para a coordenadora do Projeto São Remo, a psiquiatrização nomeia um maior isolamento e fechamento da saúde mental em seu serviço, que, como explicitado anteriormente, foi resultado, também, das escolhas feitas por um modelo de atendimento clínico na saúde do adulto que "pedia" menos sua colaboração direta. Ao mesmo tempo, a saúde mental passou a receber encaminhamentos de casos graves ou dos casos mais graves. $\mathrm{Na}$ relação com a atenção primária, a saúde mental tornava-se cada vez mais uma especialidade, atendendo o indivíduo "doente" e enfatizando diagnóstico e tratamento.

O sentido que a coordenadora do Projeto São Remo deu à expressão e sua localização como fenômeno no tempo foram diferentes daqueles entendidos pelas profissionais de saúde mental, que lembram que os atendimentos do programa eram, naquela época, mais completos, incluindo psicoterapia e terapia ocupacional, e não exclusivamente psiquiátricos convencionais. 
Para elas, sempre houve valorização de um modelo de atenção pública em saúde mental, e a chamada psiquiatrização é mais recente, estando relacionada ao aumento da demanda, ao desaparelhamento do distrito, desde o ano 2000, ao crescimento da população e da prevalência de problemas de saúde mental, à maior incidência de violência no território e à diminuição do número de profissionais do CSE. ${ }^{3}$ Incide no quadro atual de psiquiatrização o maior conhecimento e a busca da população pela saúde mental. Este quadro compele ao atendimento psiquiátrico como forma de responder às urgências e ao sofrimento da população que não pode esperar pela melhoria da rede de referências ou pela recomposição das equipes desfalcadas.

Na visão da atual coordenadora do Programa de Saúde Mental, naquele segundo período, houve uma separação entre saúde mental e os outros programas do CSEB, mas não psiquiatrização da prestação do serviço. Família.

O terceiro momento corresponde à experiência do CSEB com o Programa de Saúde da

\section{Saúde mental e Programa de Saúde da Família}

A ideia do PSF foi rejeitada pelo CSE em 1995/1996, pois havia, em seu interior, posições críticas ao programa, e nas discussões sobre o tema as posições contrárias foram majoritárias. Em 1998, houve uma experiência "inspiradora" com a figura das doulas: prática tradicional em alguns lugares da África, em que mulheres "leigas" acompanham parturientes.

E, então, em 2001, quando o programa começava a ser implantado de modo sistemático na cidade de São Paulo, ${ }^{4}$ a posição inicial de rejeição foi revista, levando-se em conta que o caráter de escola do CSEB "obrigava" a conhecer o PSF, mas, também, sugeria a adoção de um modelo próprio, diferente do modelo hegemônico na rede municipal. Tratou-se, para o centro escola, de ter um experimento com o PSF, constituindo-se, no entanto, como contraponto crítico e de produção de conhecimento sobre o programa.

O CSEB exibe uma condição de relativa autonomia que produz efeitos interessantes: no caso da implantação do PSF, parece claro que esta deve se articular à perspectiva dos Programas que vige como orientação geral da prestação de serviços. Essa maneira de agir acontece na contramão das mudanças feitas na lógica de "terras arrasadas", em que uma proposta nova deve substituir integralmente formas de organização e práticas existentes. A capacidade de negociar a entrada de novidades vindas das políticas públicas conservando sentidos e vínculos pré-existentes que enlaçam trabalhadores, modos de fazer e pensar e usuários, parece ser uma lição que este centro de saúde escola ensina. Renovar preservando é algo bastante estranho à intermitência das políticas que, por isso, muitas vezes transpiram a ideia de que em saúde está-se frequentemente começando do zero.

A proposta negociada no interior do CSEB entre os diferentes departamentos e com a Prefeitura pautou-se pela inserção do PSF na programação do CSEB, configurando uma espécie de equipamento misto (PSF e atenção primária tradicional) que, na ocasião, foi aceito pela gestão municipal, mas que vem sendo, muitas vezes, motivo de tensão entre o equipamento e a Prefeitura. ${ }^{5}$

3 Durante a realização da pesquisa, o Programa de Saúde Mental contava com uma psicóloga prestes a se aposentar e uma terapeuta ocupacional, sendo os psiquiatras e auxiliares de enfermagem maioria na composição da equipe.

4 Em função dos oito anos das gestões de Paulo Maluf e Celso Pitta na Prefeitura de São Paulo (de 1993 a 2000), com a adoção do Plano de Atendimento à Saúde (PAS), a implantação do SUS e do PSF só ocorreu de modo sistemático e contínuo a partir do governo de Marta Suplicy, que começou em 2001.

5 No final de 2009, o CSEB sofreu com a remoção, pela Prefeitura, de médicos fundamentais para garantir a capacidade de 
No lugar da formação de equipes mínimas de saúde da família - médico, enfermeira, auxiliar de enfermagem e seis agentes comunitários - como referência para grupos de 600 a 800 famílias do território de uma unidade, regra no PSF, o CSEB incorporou doze agentes que, compondo uma única equipe, trabalham com as famílias moradoras de uma favela da região. Os moradores da favela recebem cuidados de acordo com alguns princípios do PSF, especialmente no que diz respeito a visitas domiciliares e ações comunitárias. No equipamento, no entanto, são atendidos nos programas de saúde como o restante dos usuários da região. Ou seja, não existem entradas diferenciadas, coexistindo a atenção primária tradicional e a experiência com os agentes comunitários no espírito do PSF. A atenção básica, nesse caso, articula-se num espaço de invenção entre princípios do PSF e a organização em programas da atenção primária.

A presença dos agentes comunitários, segundo a coordenadora do Projeto São Remo, abre duas frentes de trabalho interessantes: a) a promoção de saúde com as visitas domiciliares e as ações comunitárias; e b) a assistência primária domiciliar (APD), envolvendo outros profissionais na ida às residências para a dispensa de cuidados especiais.

O projeto com os agentes foi tornando visíveis dimensões da atenção básica no confronto entre as proposições das leis e sua colocação em prática. A independência relativa do CSEB em relação às metas e cobranças de produtividade vindas dos gestores de governo permite experimentar essas dimensões de maneira mais aproximada daquilo que foi originalmente idealizado, valorizando elementos como: a) registros escritos do trabalho dos ACSs, com a confecção de prontuários de família detalhados; b) formação em serviço, com a oportunidade de participação dos ACSs em vários e diferentes tipos de supervisão e reuniões de trabalho; c) ênfase nas atividades de promoção de saúde, equacionando as visitas domiciliares de acordo com as necessidades concretas, e não em função de alvos quantitativos definidos de forma abstrata, e, nessa direção, as visitas domiciliares são pensadas como devendo "render" para a proposição de atividades comunitárias; ${ }^{6}$ e d) aproveitamento de informações da dinâmica da comunidade, das relações de vizinhança, das relações de poder trazidas pelos ACSs, ajudando a compor o quadro mais amplo dos problemas em que a saúde da família se apresenta.

Por outro lado, como devem integrar-se à programação do CSEB, os agentes acabam mobilizando maiores participação e inserção do CSEB na favela e, ainda, provocam um trabalho intersetorial, constituindo-se como fatores de articulação entre os programas e ações.

Neste terceiro momento, destacado pela experiência singular com o PSF, a saúde mental participou na seleção e no treinamento dos agentes comunitários, na construção de perguntas específicas sobre saúde mental no cadastro geral das famílias, na elaboração de um cadastro de saúde mental, na composição das equipes de Assistência Primária Domiciliar (APD) e na supervisão dos ACSs em saúde mental.

$\mathrm{Na}$ visão da supervisora de saúde mental, há dois aspectos que interessam à saúde mental no PSF: a) a seleção e o treinamento dos agentes comunitários; e b) a introdução de questões sobre saúde mental no cadastro geral das famílias.

No cadastro geral, foram introduzidas três perguntas sobre saúde mental: a) internações psiquiátricas pregressas; b) problemas com álcool e/ou drogas; e c) sofrimento emocional de

cobertura. Naquela ocasião, houve uma mobilização dos trabalhadores e usuários e a criação de um Conselho Popular, instância de participação democrática e aberta que não existia no centro de saúde desde 2003. A mobilização em defesa do CSEB e a perspectiva de início de uma reforma em suas dependências físicas trouxeram "um horizonte de esperança e recuperação do serviço para 2010". Em 2010, a reforma teve começo, sem que os atendimentos fossem suspensos. Ao mesmo tempo, houve a concretização da passagem de sua gestão para uma organização social que, sob muitos aspectos, abre um período de instabilidade e incerteza sobre os destinos do CSEB. Atualmente, a reforma das dependências físicas está quase pronta, e as negociações envolvendo a gestão do CSEB pela organização social estão em curso. Na saúde mental, persiste a necessidade de contratação de profissionais, embora esteja em andamento a contratação de um(a) psicólogo(a) para o lugar daquela que se aposentou.

6 Cabe notar esta concepção da visita domiciliar como, também e principalmente, uma espécie de observatório e indicador das necessidades da comunidade que podem e devem ser tratadas em atividades coletivas. 
algum tipo. Caso haja resposta afirmativa a uma ou mais dessas perguntas, procura-se preencher um segundo cadastro específico da saúde mental.

Os dois cadastros são preenchidos pelos agentes comunitários a partir de conversas com as famílias nas visitas domiciliares.

Essa tarefa demanda um refinamento da percepção dos agentes quanto aos problemas emocionais da população. O setor de saúde mental espera que os agentes detectem os casos graves e sejam sensíveis aos casos menos graves que passam despercebidos. A formação em serviço, ensejada principalmente pela supervisão, tem esta função de afinar a percepção dos problemas e sua gravidade e aprimorar o modo de contatar e conversar com os outros.

No âmbito do Programa de Saúde Mental, as mudanças introduzidas pela presença dos agentes comunitários incluem aumento de frequência de usuários da favela ao programa, inclusão de questões postas à saúde mental pela comunidade, uso do prontuário/família para atendimento, pesquisa e ensino no setor, visão mais ampla dos pacientes no contexto familiar, necessidade de fazer atendimento domiciliar psiquiátrico e/ou psicológico e realização de alguma atividade comunitária, ainda segundo a supervisora de saúde mental.

Nos comentários da equipe de saúde mental sobre a presença dos agentes comunitários destaca-se a avaliação de que eles tornam mais visíveis algumas contradições do CSEB e tensões entre a população e o sistema de saúde; entre o que é a vida, suas dores e dificuldades, e o que é a doença.

A troca com os agentes é valiosa, enriquecendo o trabalho na saúde mental, que enxerga a necessidade de valorizar seus aportes ricos em informações sobre a comunidade.

As profissionais de saúde mental ainda tematizaram a formação identitária dos agentes comunitários: trata-se de profissão em situação de fronteira ou "não lugar", sofrendo pressões para se constituir em braço de vigilância do sistema de saúde, podendo resvalar para uma atividade interventiva. Notam que muitos agentes vêm procurando categorias profissionais mais bem definidas e com atividades profissionais mais confortáveis.

Devido à falta de formação, da qual a saúde mental participou de maneira mais ampla no início da implantação do PSF no distrito do Butantã e da qual ainda participa no CSEB por meio das supervisões, percebem que o perfil dos agentes não é mais político e tende a ser caritativo ou filantrópico, perdendo sua diretriz ideológica inicial: a ênfase na assistência médica e a medicalização têm ganhado terreno em relação à promoção da saúde.

Se na avaliação da coordenadora do projeto São Remo a presença dos agentes comunitários ajudou a estabelecer pontes entre os programas e setores do CSEB entre si e com a população, para a equipe de saúde mental, além disso, os agentes permitiram e permitem o contato com dimensões e características próprias de um lugar precário, não hegemônico, com o qual é possível identificar tanto o campo da saúde mental como o CSEB.

O sofrimento das auxiliares de enfermagem da saúde mental assemelha-se ao sofrimento dos agentes pela necessidade de construir limites para o trabalho, na relação direta com população e suas demandas. E o sofrimento de todos da saúde mental advém, como aquele dos agentes comunitários, do lugar intersticial: "a saúde mental é o paraíso das contradições entre abrir a porta e o montante de questões que aparecem", no dizer de uma médica da equipe. A saúde mental, tal como a atividade dos agentes, abre-se à configuração de um retrato dos problemas da população, pois ali tudo pode ser falado, reivindicado, expressado.

A relação com os agentes é boa porque amplia o acesso e "oferece remédio, ouvido, compreensão", ainda, segundo a mesma médica. Mas, ao mesmo tempo, denuncia os impasses de visitar as famílias, descobrir as necessidades e depois não conseguir responder por falta de rede e intersetorialidade, ou não conseguir dar continuidade ao atendimento. 
A posição "meio pária" do CSEB, por seu turno, permitiu que ele continuasse a fazer um trabalho consistente: "não estar em lugar nenhum tem o ônus de receber menos verba, mas tem o bônus de experimentar com certa liberdade e manter uma referência com as origens", considera a médica.

Esta experimentação está no cerne das práticas que enlaçam saúde mental, saúde da família e atenção básica, equipe de saúde mental e agentes comunitários de saúde na história mais recente do CSEB.

\section{Saúde mental, atenção primária e atenção básica}

A entrevista com a coordenadora do Projeto de Saúde Mental do CSEB abriu um conjunto de comentários e interpretações articulando saúde mental, atenção primária e atenção básica. Uma análise sócio-histórica das políticas públicas de saúde mental no Brasil (Pereira, Rizzi \& Costa, 2008), somada à singularidade da situação do Programa de Saúde Mental no CSEB, dá o tom para as questões desde aí suscitadas.

O modelo do Programa de Saúde Mental no CSEB foi, desde sua construção inicial, de atenção primária. Como explicado anteriormente, tratou-se da instalação de uma equipe de saúde mental como porta de entrada para a clientela de uma unidade básica de saúde, neste caso um centro de saúde escola.

Este modelo é filiado à estrutura piramidal tradicional de prestação de serviços em saúde, reformulada, no Estado de São Paulo, no governo de Franco Montoro (1983-1987), no bojo da reforma assistencial que antecedeu o SUS. Nela, se buscava inverter a pirâmide das atenções primária, secundária e terciária, que, na saúde mental, era composta por uma base ínfima de atenção primária, seguida de um miolo mediano de atenção secundária e um topo largo e robusto de atenção terciária, representado pelos hospitais psiquiátricos. A inversão aspirava diminuir o "parque manicomial" e aumentar o atendimento ambulatorial e a atenção primária nos centros de saúde e unidades básicas.

Na sequência, houve certa concomitância da reforma sanitária que instituiu o SUS e o PSF e a reforma psiquiátrica, que, como vertente da luta antimanicomial, centrou suas forças no desmancho do setor terciário. Esses dois movimentos, até certo ponto paralelos, incidem sobre a ideia e as práticas de atenção primária em saúde mental e a permanência do Programa de Saúde Mental no CSEB encarna e expressa muitos dos problemas e preocupações desta convergência. ${ }^{?}$

A reforma psiquiátrica de cunho antimanicomial realiza, pouco a pouco, a substituição dos hospitais psiquiátricos pelos Centros de Atenção Psicossocial (CAPSs) que devem "segurar pacientes que poderiam ser internados" e "fazer um trabalho de desinstitucionalização, de inclusão, de desestigmatização que evitaria que o resto da sociedade internasse". Os CAPSs são destinados àquelas pessoas com "transtornos graves" e provocam a preocupação com o atendimento da maioria da população que sofre com "transtornos moderados ou leves".

Paralelamente, o avanço do PSF, a partir de 2001, na cidade de São Paulo, tende a retirar as equipes de saúde mental das unidades básicas ou, o que dá no mesmo, tende a fazer desaparecer a saúde mental como atenção primária.

$\mathrm{Na}$ configuração atual da política de saúde, ainda na visão da coordenadora do programa de saúde mental, as pessoas com "transtornos moderados e leves" que ficaram "sem

7 Sobre os temas da reforma psiquiátrica, do SUS e do PSF ver: Cohn (2005, 2009), Junqueira (2001), Luzio e L'Abbate (2006), Schmidt (2004) e Viana e Dal Poz (2005). 
lugar" podem e devem ser cuidadas pelas equipes de PSF, contando com o apoio dos profissionais de saúde mental como retaguarda. Trata-se do modelo de matriciamento dos Núcleos de Apoio à Saúde da Família (NASFs) que deverão se articular em torno de duas práticas principais, juntando equipes de PSF e especialistas: supervisão e discussão de casos e corresponsabilidade em alguns atendimentos.

Na crítica desta coordenadora, nesta situação, destacam-se alguns pontos cruciais: a) na atenção básica, com o PSF, a saúde mental transforma-se em especialidade, enquanto na atenção primária era e é uma porta de entrada específica; b) na atenção básica a saúde mental matricia, principalmente, médicos, enfermeiros e agentes comunitários numa perspectiva médico-assistencialista - a saúde mental reduz-se a uma especialidade médica; c) a saúde mental como matriciadora de PSF corre o risco de só poder oferecer ou sugerir remédio e "vida social" (participação em atividades socializantes dos mais diversos tipos); d) o matriciamento corre o risco de tornar-se atendimento em saúde mental, porque os profissionais da área podem ficar tentados a assumir a prestação de serviço no lugar das equipes de PSF "despreparadas" para tal empreitada ou porque os próprios profissionais de saúde mental não foram formados para atuar no território como apoiadores.

No CSEB, tendo em vista seu caráter de unidade mista e a singularidade dessa "mistura" que não é propriamente feita de atenção primária e equipes de PSF, mas, sim, como já foi explicado, da inserção dos agentes comunitários na programação de saúde, o Programa de Saúde Mental encara uma experiência dupla: de um lado, o atendimento da população em geral, atendimento que vem se tornando mais psiquiátrico, medicamentoso, conservando, contudo, grupos de terapia ocupacional e alguma agenda para psicoterapias individuais; de outro, a relação com os agentes comunitários de saúde.

$\mathrm{Na}$ relação com os agentes comunitários de saúde, atualizam-se perguntas e preocupações derivadas da análise da política atual. Alguns exemplos: a) a preocupação em identificar e distinguir os problemas de saúde mental e suas gravidades norteando o tipo de formação e de informação que constitui a supervisão e o tipo de ação possível no âmbito de uma combinação peculiar de atenção primária e básica; b) o estudo de casos difíceis tomado como ocasião de aprendizagem tanto para a equipe de saúde mental quanto para os ACSs; c) a tentativa de entender o que é um ACS atendendo um "caso de psicose"; d) a provocação do cuidado em saúde mental como prevenção e o risco de medicalização da população e da mentalidade dos ACSs, entre outras.

Se é verdade que o Programa de Saúde Mental vem se psiquiatrizando, o contato com os agentes comunitários introduz uma tensão nessa psiquiatrização.

As supervisões e a formação, estando intimamente ligadas, oferecem um terreno fecundo para compreender do que é feita essa tensão.

\section{Supervisão em saúde mental: formação e confronto}

A tensão anteriormente referida pode ser descrita, num primeiro momento, como entre um modelo de serviço de saúde mental composto por atendimento psiquiátrico, psicológico e grupos de terapia ocupacional aos quais a clientela se acomoda, ou não, e um convite que vem dos ACSs e da comunidade para um movimento do serviço no sentido de ler e compreender necessidades não contempladas pelo modelo.

Nas entrevistas com a supervisora de saúde mental e com os ACSs e, também, nas observações das supervisões, foi possível distinguir uma série de demandas, por assim dizer, dirigidas do programa de saúde mental aos ACSs e, destes, ao programa que se destaca dos 
objetivos formativos principais, que são ensinar os agentes a diferenciar níveis de gravidade dos transtornos mentais e ensinar como falar sobre e se aproximar do sofrimento emocional junto à população.

Se, por um lado, a supervisão promove o refinamento da percepção e da compreensão dos agentes sobre o sofrimento emocional, por outro, os agentes respondem aumentando a visibilidade dos casos graves e acolhendo os casos moderados e leves, exercendo uma função de vigilância e ampliando a esfera de influência da saúde mental: a colaboração muda o perfil dos agentes e altera, também, o conhecimento do programa de saúde mental sobre a população atendida pelo PSF, no que diz respeito tanto ao acesso a "casos" que de outra forma não chegariam ao setor quanto à oportunidade de entendê-los no contexto mais abrangente da família e da comunidade ou bairro.

A construção de vínculos é condição para as ações de cuidado dos agentes com a população e, ao mesmo tempo, objeto de um cuidado dispensado aos agentes nas supervisões.

Os agentes que têm casos falam, algumas vezes os colegas participam, outras a conversa permanece entre aquele que trouxe o caso e a supervisora. Esta, por sua vez, intervém, sobretudo, com perguntas sobre a visita domiciliar, informações sobre como a ciência médica leria o caso relatado e orientações para a ação dos agentes.

Os comentários têm, por um lado, o sentido de provocar ou ensinar os agentes a "fazer falar" o sintoma: se o usuário fala em depressão ou ansiedade, é preciso aprender a perguntar sobre a experiência singular daquela ansiedade ou depressão.

Há ênfase na necessidade dos agentes acercarem-se do que vive o usuário, sob a capa de uma palavra tomada do repertório médico. Alguns agentes fazem isso com desenvoltura e/ou deparam com usuários dispostos a falar; outros parecem não ter clareza sobre o sentido desse "fazer falar", sentem dificuldade em perguntar e/ou se defrontam com usuários calados ou reservados.

Essas dificuldades remetem ao espaço problemático onde a condução adequada de tarefas de cuidado depende de qualidades subjetivas e pessoais cuja aquisição não é possível por meio de um treinamento instrumental.

A supervisão é uma prática com vocação para acolher e trabalhar subjetivamente as implicações dos vínculos de cuidado. No entanto, precisa lidar com a questão delicada de negociar condições nas quais trabalhar a si mesmo para trabalhar possa ser assumido como propósito formativo. A tensão entre treinamento e formação perpassa a supervisão.

Um agente, por exemplo, aponta que o formulário de saúde mental não é suficientemente minucioso em relação às perguntas e questões nas quais o setor está interessado. Parece que a forma mais administrada da supervisão ou da relação da saúde mental com os agentes reflete-se, aqui, na relação de exterioridade deste agente com a aplicação do questionário, mas, também, a reclamação pode sugerir uma maneira de defender-se deste estilo e denunciá-lo: a "acusação" ao questionário encobre ou protege as dificuldades encontradas pelo agente e, ainda, denuncia seu desejo de contar com um apoio melhor para entrevistar os usuários. Um questionário "melhor", "mais completo", serve, talvez, como metáfora desse desejo.

Os comentários da supervisora contemplam, ainda, ensinamentos sobre como diagnosticar sem estigmatizar, comparações e aproximações entre saberes da ciência médica e crenças populares e considerações sobre a "normalidade" de certas "anormalidades".

Os diagnósticos ou informações diagnósticas são tratados com precaução, tentando evitar sua apropriação como estigma ou sinal de anormalidade.

As histórias trazidas pelos agentes são oportunidades para a apresentação das visões médicas e psiquiátricas. Como legendas, explicam e inscrevem as histórias no léxico 
especializado: "chamamos isso de somatização"; "trata-se, sim, de uma depressão, que pode estar associada ao enfarte, pois há pesquisas que mostram alto índice de depressão depois de acidentes ou operações cardiovasculares"; "o uso de anfetaminas é comum em caminhoneiros e pode levar à ansiedade, associada ao estresse da própria profissão".

O saber especializado enseja certo tipo de entendimento das histórias, de valor científico e, portanto, considerado útil aos agentes. Essa espécie de informação associa-se a outro tipo de intervenção formativa que busca assinalar o valor de algumas crenças para o imaginário popular. Essas crenças têm uma tradução ou explicação científica, na maioria das vezes.

Uma senhora que diz ser tomada por espíritos foi um exemplo anotado em supervisão. A supervisora frisa que, na experiência daquela mulher, os espíritos são organizadores potentes, e é preciso respeitar esta crença; para a psiquiatria, porém, há pessoas que têm facilidade para entrar em um estado alterado de consciência e ficam, então, em transe. Esses estados podem ser modos de lidar com conflitos, nos quais a pessoa se evade, desmaiando ou dissociando.

O exemplo ilustra uma comparação, uma colocação em paralelo: necessidade de respeitar a religiosidade e modos de pensar e sentir próprios da experiência religiosa do usuário e a explicação científica para os mesmos fenômenos. Essa colocação em paralelo enseja a interrogação sobre a pertinência de um tratamento religioso para os transes, mostrando a presença de abertura para acolher formas de cuidado de outras esferas sociais e culturais.

Existe, também, uma preocupação da supervisora de colocar certos "mecanismos" ou "fenômenos" psicológicos como comuns a todos, como recurso pedagógico para combater o preconceito e a estigmatização por parte dos agentes em relação a usuários.

É ilustrativa uma referência da supervisora à ambivalência de sentimentos como base da conduta de uma mulher que permanece com o marido que a espanca. A ambivalência é comum, segundo a supervisora, acontecendo "com todos nós": "queremos por uma parte e não queremos por outra". A mulher que apanha do companheiro e continua com ele, portanto, expressa algo comum, normal.

Os meios formativos - transmissão de informação científica e de pesquisa, orientação quanto à importância de os agentes fazerem os usuários falar de suas experiências em relação aos sintomas, ênfase no discurso de respeito às práticas e concepções religiosas, atenção ao caráter excepcional ou anormal de certas condutas e sentimentos dos usuários, buscando atenuar eventuais preconceitos - fazem pensar que os agentes ouvem do supervisor que é preciso respeitar os valores culturais e religiosos da população e, ao mesmo tempo, aprender as interpretações para o sofrimento e para os fenômenos oferecidas pela ciência, bem como desenvolver uma atitude receptiva às múltiplas e diversas maneiras de cuidar.

Essa orientação evidencia o lugar fronteiriço do agente comunitário que o coloca como intermediário e tradutor na relação entre o sistema de saúde e as populações assistidas.

Na supervisão, os agentes são convidados a falar, trazendo os casos ou oferecendo as informações que a equipe de saúde mental pede.

Existe pouca intervenção dos agentes no relato e na discussão dos casos de seus colegas. Porém, é frequente intervirem contando o que sabem sobre alguém ou alguma família. São especialmente dispostos para contar as histórias de vida dos indivíduos e famílias que conhecem: por que o irmão de "fulana" apanhou na rua? O agente não sabe. Mas os colegas imediatamente contam que ele brigou no bar, quebrou a perna do filho de não sei quem e levou o troco.

Quando se trata de interpretar ou compreender o caso, alguns são mais ativos, elaborando suas percepções e recomendações. Uma agente relata o caso de uma moça que 
apanha do marido e atribui seu nervosismo e depressão à situação de vida que está passando e não vê necessidade de atendimento psiquiátrico. As psiquiatras concordam.

Outros arriscam interpretações e oferecem informações, dados históricos que vão compondo o contexto ou o quadro de vida de um usuário ou de sua família.

A participação dos agentes nas supervisões, além do oferecimento de informações e histórias e do relato e discussão de tarefas estabelecidas nesse coletivo, como, por exemplo, a aplicação de cadastro de saúde mental ou a realização de uma visita domiciliar com algum propósito singular, inclui falas próprias de interpretação e compreensão dos casos e alguma confrontação ou resistência às interpretações especializadas.

Em alguns momentos, diferentes interpretações são confrontadas: uma senhora tem dores por causa de problemas ósseos, como artrite, artrose, bico de papagaio, tendinite; quando a supervisora aventa a possibilidade de somatização e do uso evasivo das dores, uma agente protesta dizendo que a senhora sente mesmo as dores que diz sentir. A "psicologização" pareceu à agente uma espécie de afronta ao sofrimento físico.

O saber dos agentes aparece, ocasionalmente, na forma condensada de provérbios e máximas. Trata-se da sabedoria associada ao senso comum que remete à elaboração da experiência de vida de coletividades feita em tempos muito prolongados: ${ }^{8}$ uma agente concorda com o encaminhamento de uma usuária para uma atividade com a expressão "mente vazia é oficina do diabo".

A esses modos de saber fazer juntam-se valores, traduzindo julgamentos. A "casa bagunçada" elucida o julgamento que associa a desarrumação da moradia com a da família.

Os agentes comunitários entendem que seu trabalho ajuda sobremaneira a diminuir o preconceito da população em relação ao serviço de saúde mental e faz crescer o interesse e a demanda por esse serviço.

Uma opinião comum aos agentes é a de que o cuidado em saúde mental acaba se concentrando muito na medicação. Para eles, haveria necessidade de psicoterapia, de conversa, porque as doenças "da cabeça" são diversas daquelas do corpo para as quais os remédios bastariam. Veem que a população tem medo de ficar dependente do remédio, embora mostre atitudes híbridas de medo e desejo.

Os ACSs, por sua vez, acham que a loucura e o sofrimento mental estão mais ligados a um modo de ser dos indivíduos ou às histórias de vida do que a uma doença. Por isso, também, o remédio que é útil para o corpo pode ser insuficiente ou mesmo ineficaz para a "cabeça".

Em sua crítica ao cuidado dispensado pela equipe de saúde mental, aparece, portanto, aquela sobre o uso de remédios e a observação de que os pacientes do setor passam anos tomando medicação sem, no entanto, melhorarem de forma definitiva: "passam anos e anos tomando remédio, com períodos de melhora intercalados com crises", observa uma agente.

A equipe de saúde mental também demonstra preocupação com o uso intenso e exclusivo de medicamentos: por um lado, quando enfrenta a demanda alta, acaba medicando como uma maneira de aliviar um sofrimento presente que não encontra outro lugar, de conversa, onde ser cuidado; e, por outro, na formação dos agentes, procurando torná-los capazes de dar continência ao sofrimento, embora, em grande parte, trate de habilitá-los para perceber e informar os problemas da comunidade.

A visão epidemiológica da saúde mental, diferenciando transtornos leves, moderados e graves, é um organizador potente das ações de cuidado e de formação dos agentes.

Os agentes parecem não experimentar dificuldade na identificação dos chamados casos graves, exuberantes na produção de sintomas como delírios e alucinações e que impressionam 
pelo estranhamento e, algumas vezes, medo que provocam. Estes, sem dúvida, para eles, requerem consultas psiquiátricas.

Os chamados casos leves ou de média gravidade já oferecem maior dificuldade para diferenciar. No entanto, na abordagem desses casos, foi possível presenciar, por parte dos agentes, um trabalho de reflexão sobre o sentido do sofrimento atribuído, na maioria das vezes, às histórias de vida, e não a uma doença. Revela-se nos agentes a percepção aguda de efeitos emocionais e afetivos de vidas difíceis e a concepção do sofrimento expresso nas depressões, ansiedades e sintomas psicossomáticos, principalmente como modos de responder às dificuldades intransponíveis da vida.

A percepção dos problemas da saúde mental provoca maneiras de dizer interessantes, que guardam uma certa distância em relação à nomenclatura psiquiátrica. Alguns exemplos: "conversa certinho, mas está muito agitado"; "parece normal, por fora".

As ponderações das agentes, nas supervisões, faziam, frequentemente, o papel de contraponto às tentações da medicalização, remetendo às formas de existência social e familiar a origem do que tenderia a ser interpretado como doença de um indivíduo, embora os chamados transtornos graves, as psicoses, fossem lidos mais comumente como a doença de alguém.

Há, em certo sentido, uma expectativa da saúde mental quanto à atuação dos agentes no âmbito da vigilância, e estes, por seu turno, esperam que a saúde mental possa dar conta dos problemas encontrados. Mas a supervisão não se reduz à confrontação dessas expectativas, apresentando-se como exemplo profícuo de prática em que a convivência de saberes é possível, gerando, algumas vezes, formas de cuidado peculiares e adequadas e, outras, a certeza de que há um longo caminho de construção entre atenção básica e saúde mental a percorrer.

\section{Referências}

Benjamin, W. (1936/1985). O narrador: considerações sobre a obra de Nikolai Leskov (obras escolhidas, v. 1). São Paulo: Brasiliense.

Clifford, J. (2002). A experiência etnográfica: antropologia e literatura no século XX. Rio de Janeiro: UFRJ.

Cohn, A. (2005). A saúde na previdência social e na seguridade social: antigos estigmas e novos desafios. In A. Cohn \& P. E. Elias (Orgs.), Saúde no Brasil: políticas e organização de serviços. São Paulo: Cortez/CEDEC.

Cohn, A. (Org.) (2009). Saúde da família e SUS: convergências e dissonâncias. Rio de Janeiro: Beco do Azougue. São Paulo: CEDEC.

Geertz, C. (1989). A interpretação das culturas. Rio de Janeiro: Livros Técnicos e Científicos.

Geertz, C. (2002). Obras e vidas: o antropólogo como autor. Rio de Janeiro: UFRJ.

Giordano Jr., S. \& Pereira, F. L. M. (1996). Saúde mental. In L. B. Schraiber, M. I. B. Nemes \& R. B. MendesGonçalves (Orgs.), Saúde do adulto: programas e ações na Unidade Básica. São Paulo: Hucitec.

Instituto Nacional de Assistência Médica da Previdência Social (1983). Programa de reorientação da assistência psiquiátrica. Brasília: MPAS/CCS.

Junqueira, V. (2001). Saúde na cidade de São Paulo (1989 a 2000) (Observatório dos Direitos do Cidadão: acompanhamento e análise das políticas públicas da cidade de São Paulo, 3). São Paulo: Polis/PUC-SP.

Luzio, C. A. \& L'Abbate, S. (2006). A reforma psiquiátrica brasileira: aspectos históricos e técnico-assistenciais das experiências de São Paulo, Santos e Campinas. Interface: Comunicação, Saúde, Educação, 10 (20), 281-298.

Pereira, L. M. F., Rizzi, H. J. \& Costa, A. C. F. (2008). Análise sócio-histórica das políticas públicas em saúde mental no Brasil. In Lancman, S. (Org.), Políticas públicas e processos de trabalho em saúde mental. Brasília: Paralelo 15. 
Schmidt, M. L. S. (2004). Plantão psicológico, universidade pública e política de saúde mental. Estudos em Psicologia, Campinas, 21 (3), 173-192.

Viana, A. L. D. \& Dal Poz, M. R. (2005). A reforma do sistema de saúde no Brasil e o Programa de Saúde da Família. Physis: Revista de Saúde Coletiva, 15 (suplemento), 225-264.

\section{Endereço para correspondência}

maluschmidt@terra.com.br

Recebido em: 15/04/2012

Revisado em: 30/11/2012

Aprovado em: 04/12/2012 